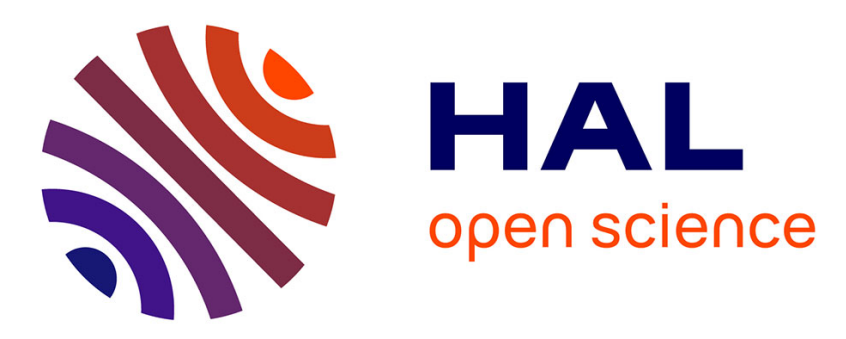

\title{
Détection sérologique des virus du court-noué de la vigne par le test ELISA
}

Bernard Walter, André Vuittenez, Jean Kuszala, Gilbert Stocky, Jacqueline

Burckard, Marc H. V. van Regenmortel

\section{- To cite this version:}

Bernard Walter, André Vuittenez, Jean Kuszala, Gilbert Stocky, Jacqueline Burckard, et al.. Détection sérologique des virus du court-noué de la vigne par le test ELISA. Agronomie, 1984, 4 (6), pp.527-534. hal-00884668

\section{HAL Id: hal-00884668 https://hal.science/hal-00884668}

Submitted on 1 Jan 1984

HAL is a multi-disciplinary open access archive for the deposit and dissemination of scientific research documents, whether they are published or not. The documents may come from teaching and research institutions in France or abroad, or from public or private research centers.
L'archive ouverte pluridisciplinaire HAL, est destinée au dépôt et à la diffusion de documents scientifiques de niveau recherche, publiés ou non, émanant des établissements d'enseignement et de recherche français ou étrangers, des laboratoires publics ou privés. 


\section{Détection sérologique des virus du court-noué de la vigne par le test ELISA.}

Bernard WALTER, André VUITTENEZ, Jean KUSZALA, Gilbert STOCKY, Jacqueline BURCKARD (*) \& Marc H. V. VAN REGENMORTEL $\left(^{*}\right)$

I.N.R.A., Station de Pathologie végétale, 28, rue de Herrlisheim, F 68021 Colmar Cedex

(*) Institut de Biologie moléculaire et cellulaire du C.N.R.S., 15, rue Descartes, F 67084 Strasbourg Cedex

Mots clés additionnels : Népovirus, mosaique de l'arabis, sélection sanitaire, diagnostic viral.

\section{Serological detection of nepoviruses of grapevine by ELISA.}

Two nepoviruses, arabis mosaic virus and grapevine fanleaf virus, were detected in grapevines by direct and indirect ELISA methods. The sensitivity and specificity of both methods are very similar.

Different sampling procedures were compared with respect to their suitability for routine screening of infected plant material. Reliable detection of the viruses by ELISA was no longer achieved in leaves in the late autumn when grapevine rootlets had to be used as a source of virus.

Additional key words : Arabis mosaic virus, grapevine fanleaf virus, nepoviruses, sanitary selection, diagnosis.

\section{INTRODUCTION}

A cause de sa grande sensibilité, la technique ELISA (enzyme-linked immunosorbent assay) s'est révélée très utile pour la détection sérologique des népovirus de la vigne tant chez les hôtes herbacés que chez la vigne elle-même (VOLLER et al., 1976 ; THRESH et al., 1977 ; GONSALVES, 1979 ; RAMSDELL et al., 1979 ; WALTER et al., 1979 ; BOVEY et al., 1980 ; ENGELBRECHT, 1980 ; JIMENEZ \& ĠOHEEN, 1980 ; KOLBER et al., 1980 ; TANNE, 1980 ; VUITTENEZ, 1980 ; JANKULOVA et al., 1982 ; SHANMUGANATHAN \& FLETCHER, 1982).

La méthode ELISA la plus utilisée est la méthode sandwich directe (CLARK \& ADAMS, 1977) qui présente cependant 2 inconvénients :

1) sa trop grande spécificité au niveau de la souche du virus (BARBARA et al., 1978; KOENIG, 1978 ; ROCHOW \& CARMICHAEL, 1979 ; BAR JOSEPH \& SALOMON, 1980 ; UYEMOTO, 1980) ;
2) la nécessité de préparer un conjugué enzymeanticorps pour chaque virus que l'on souhaite diagnostiquer.

La méthode ELISA indirecte ne présente pas ces inconvénients car elle permet la détection d'une gamme plus large de souches (VAN REGENMORTEL $e t$ al., 1980 ; VAN REGENMORTEL \& BURCKARD, 1980 ; DEVERGNE et al., 1981 ; RYBICKI \& VON WECHMAR, 1981 ; LOMMEL et al., 1982) et ne requiert que la préparation d'un seul conjugué (par exemple des anticorps de chèvre anti-globulines de lapin). La technique sandwich indirecte est bien adaptée au diagnostic viral dans les extraits bruts de plantes, mais elle nécessite la préparation de 2 sérums anti-virus à partir de 2 espèces animales différentes dont les immunoglobulines ne présentent pas de réaction croisée : lapin et poule par exemple (VAN REGENMORTEL, 1982).

Dans ce travail, nous avons comparé l'efficacité des techniques ELISA directe et indirecte pour le dépistage chez la vigne des népovirus provoquant la maladie du 
court-noué ; nous avons également comparé ces techniques immunoenzymatiques avec la méthode de floculation du latex (QUERFURTH \& PAUL, 1979).

Le broyage manuel des plantes à indexer est souvent long et pénible, notamment pour la préparation d'échantillons en grand nombre dans les programmes de sélection sanitaire. Des tentatives pour alléger cette étape ont été proposées, par exemple, en extrayant le jus de feuilles à l'aide d'une presse POLLÄHNE ou en utilisant des disques non broyés de feuilles infectées (MARCO \& COHEN, 1979, ROMAINE et al., 1981).

Nous avons cherché à établir un test rapide de détection du court-noué adapté au contrôle sanitaire d'un matériel végétal important destiné à la multiplication de la vigne ; bois prélevés par sondage dans des parcelles de pieds mères de porte-greffe ou de Vitis vinifera, boutures ou plants greffés produits commercialement et prêts à la vente.

\section{MATÉRIEL ET MÉTHODES}

Nos essais ont porté sur les 2 népovirus, agents du court-noué de la vigne en France : grapevine fanleaf virus (GFV) et arabis mosaic virus (AMV). Une souche de référence de l'AMV, obtenue de CADMAN en 1962, a été utilisée pour différents essais comparatifs. Les origines cles vignes malades éprouvées dans les tests étaient déjà connues à la suite d'épreuves antérieures (notamment pour celles inoculées par greffe à l'aide d'origines connues de GFV ou d'AMV), permettant de disposer de plantes infectées par ces 2 virus isolément ou en association. Les vignes saines étaient issues de clones sélectionnés sans virus initialement; leur indexage devait constituer un contrôle a posteriori du maintien de leur bon état sanitaire.

Les séries de tests avec le matériel développé en serre, qui se sont échelonnées sur une période de 3 mois, ont permis de juger de la fiabilité des méthodes, selon le degré de vieillissement des organes en serre. La sensibilité des méthodes a aussi été éprouvée en associant des prélèvements de vignes saines et des prélèvements de vignes malades en proportion variable.

Les différents isolats de GFV (F13, GH) et d'AMV (SYRAH, CADMAN) sont maintenus en serre sur Chenopodium quinoa.

\section{A. Préparation des échantillons}

Pendant la période de végétation au vignoble, de jeunes feuilles sont prélevées à l'extrémité des sarments sur souches adultes de Vitis vinifera ou d'hybrides porte-greffe.

En hiver, les échantillons de feuilles ou de radicelles sont prélevés sur des plants de vigne en pots, obtenus à partir de boutures de sarments ayant été placées $24 \mathrm{~h}$ en anaérobiose partielle sous l'eau pour lever la dormance, puis forcées en serre. Dans ce cas, les prélèvements étaient effectués, soit peu après le débourrement (feuilles), soit après 3 mois de culture en serre (feuilles et radicelles).

$1 \mathrm{~g}$ de tissus (feuilles de $C$. quinoa, radicelles ou feuilles de vigne) est broyé soit dans un mortier, soit à l'aide d'un broyeur à cylindre (presse POLLÄHNE) en présence de $4 \mathrm{ml}$ de tampon PBS-T-PVP pH 7,4, additionné de 2,5 p. 100 de nicotine dans le cas d'échantillons de vigne. Dans certaines expériences les échantillons sont constitués de disques de limbe de $25 \mathrm{~mm}$ de diamètre, provenant de vignes malades ou saines, individuellement ou en associant un disque de vigne malade et 49 de vigne saine (dil. 1/50), et broyés de la même façon. Les extraits sont centrifugés pendant $15 \mathrm{mn}$ à $6000 \mathrm{~g}$. Dans le cas des extraits destinés à des tests comparatifs en ELISA et latex, le broyage des tissus de vigne est effectué dans une solution de 2,5 p. 100 de nicotine dans l'eau ; les surnageants, après centrifugation, sont ensuite mélangés à un volume égal de solution contenant une concentration double des constituants des tampons (PBS-T-PVP pour ELISA et Tris-PVP pour latex).

Parallèlement, des disques de $5 \mathrm{~mm}$ de diamètre sont découpés à l'aide d'un emporte-pièce dans les feuilles de $C$. quinoa et de vigne et broyés comme cidessus à raison de $4 \mathrm{ml}$ de milieu/g ou immergés directement dans les cupules ELISA contenant $200 \mu \mathrm{l}$ de milieux de diffusion. Les milieux utilisés sont : $\mathrm{H}_{2} \mathrm{O}$; tampon PBS; PBS + mercaptoéthanol 0,2 p. 100 ; PBS + DIECA 0,1 p. $100 ;$ PBS + Tween 20 0,05 p. $100+$ PVP 2 p. 100 ; nicotine 1 ou 2,5 p. 100 dans $\mathrm{H}_{2} \mathrm{O}$ ou PBS.

\section{B. Préparation des antisérums}

Les virus AMV et GFV sont purifiés à partir de C. quinoa après clarification au butanol-chloroforme, précipitation au polyéthylèneglycol, ultracentrifugation et fractionnement sur gradient de saccharose. Chaque semaine on injecte $1 \mathrm{ml}$ d'extrait purifié, par piqûres intramusculaires dans la cuisse des lapins ou des poules, en présence de $1 \mathrm{ml}$ d'adjuvant incomplet de Freund. Les extraits contiennent de 30 à $60 \mu \mathrm{g} / \mathrm{ml}$ de GFV, de 75 à $100 \mu \mathrm{g} / \mathrm{ml}$ d'AMV.

Les titres des antisérums sont déterminés par double immunodiffusion en gélose en présence de $\mathrm{NaCl}$ $0,15 \mathrm{M}$.

\section{Purification des IgG de lapins et préparation des conjugués}

L'albumine et d'autres protéines du sérum des lapins sont précipitées par addition de rivanol (2éthoxy-6,9-diaminoacridine lactate) à 0,09 p. 100 final (HARDIE \& VAN REGENMORTEL, 1977). Les IgG sont recueillies ensuite par précipitation au sulfate d'ammonium $2 \mathrm{M}$ final, redissoutes dans un petit volume d'eau distillée, dialysées contre du tampon PBS 1/2, ajustées à une concentration de $1 \mathrm{mg} / \mathrm{ml}\left(\mathrm{E}_{1}^{0,1 \% 0} \mathrm{~cm}^{1}=1,4\right)$ et conservées à $-20^{\circ} \mathrm{C}$.

La phosphatase alcaline (SIGMA, VII-S) est couplée aux IgG en présence de glutaraldéhyde à 0,06 p. 100 (AvRAMEAS, 1969). Les conjugués sont conservés à $4{ }^{\circ} \mathrm{C}$.

\section{Purification des IgY de poules}

Les jaunes d'œufs successifs d'une poule immunisée avec le virus sont rassemblés et les IgY en sont extraites par précipitations progressives au polyéthylèneglycol 6000 à 3,5 p. 100 puis 12 p. 100 selon la méthode décrite par POLSON et al. (1980). Les IgY sont reprises dans du tampon phosphate $0,01 \mathrm{M} \mathrm{pH}$ 
7,5 contenant $0,1 \mathrm{M}$ de $\mathrm{NaCl}$ et 0,01 p. $100 \mathrm{de} \mathrm{NaN}_{3}$ à raison de $10 \mathrm{ml}$ pour 3 œufs. Le PEG restant est éliminé par un traitement avec un volume de chloroforme et les IgY sont conservées à $-20^{\circ} \mathrm{C}$.

\section{E. Méthode Eusa directe}

Les cupules des cuvettes PAK-GILFORD ou des plaques GREINER M 29 A sont tapissées avec $200 \mu \mathrm{l}$ d'IgG de lapins diluées dans du tampon carbonate de sodium $\mathrm{pH} 9,6$ et incubées pendant 4 à $5 \mathrm{~h}$ à $37^{\circ} \mathrm{C}$. Après 3 rinçages à l'aide du tampon $\mathrm{PBS} \mathrm{pH} 7,4$ contenant $0,05 \mathrm{p} .100$ de Tween 20 (PBS-T), on ajoute $200 \mu \mathrm{l}$ d'extraits de feuilles de vigne ou de $C$. quinoa préparés comme décrit ci-dessus ou $200 \mu 1$ de milieu de diffusion dans lesquels on immerge des disques de feuilles. Les extraits sont incubés pendant une nuit à 6 ou à $20^{\circ} \mathrm{C}$. Après 3 nouveaux rinçages, $200 \mu \mathrm{l}$ de conjugué phosphatase-IgG lapin dilué dans du PBS-T contenant 2 p. 100 de PVP et 0,2 p. 100 d'ovalbumine sont incubés pendant 5 à $6 \mathrm{~h}$ à $37^{\circ} \mathrm{C}$. Les cuvettes sont à nouveau rincées et $250 \mu \mathrm{l}$ de substrat ( $\mathrm{p}$-nitrophényl phosphate de 0,6 à $1 \mathrm{mg} / \mathrm{ml}$ dans un tampon diéthanolamine $0,1 \mathrm{M} \mathrm{pH} \mathrm{9,8)} \mathrm{sont} \mathrm{mis} \mathrm{à} \mathrm{incuber} \mathrm{à} \mathrm{température}$ ambiante pendant des durées variables. La réaction est mesurée par lecture de la densité optique à $405 \mathrm{~nm}$ à l'aide d'un lecteur GILFORD EIA PR 50 ou d'un lecteur DYNATECH micro ELISA MR 590.

\section{F. Méthode EuISA indirecte}

Les cuvettes sont tapissées avec des IgY de poules comme décrit ci-dessus. Après rinçage et incubation des antigènes, $200 \mu \mathrm{l}$ d'IgG de lapin $(1$ à $2,5 \mu \mathrm{g} / \mathrm{ml})$ sont incubés pendant $3 \mathrm{~h}$ à $37^{\circ} \mathrm{C}$. Les cuvettes sont rincées, puis on ajoute $200 \mu 1$ de conjugué préparé avec des immunoglobulines de chèvre anti-IgG de lapin. Après $3 \mathrm{~h}$ d'incubation à $37^{\circ} \mathrm{C}$, la réaction enzymatique est faite comme précédemment.

\section{G. Test de floculation au latex}

La technique utilisant du latex préenrobé par la protéine $\mathrm{A}$, c'est-à-dire la méthode PALlaS (QUERFURTH \& PAUL, 1979), a été appliquée.

\section{RÉSULTATS}

Les titres des anti-sérums des lapins et des préparations d'IgY purifiées des œufs sont très comparables et atteignent des valeurs supérieures à $1 / 1000$ après 5 injections. Le titre des réactions avec les protéines normales est inférieur à $1 / 32$, celui des réactions hétérologues entre les 2 virus AMV et GFV est le plus souvent inférieur à $1 / 32$.

Différents milieux ont été essayés dans lesquels les feuilles de $C$. quinoa ou de vigne ont été broyées. Si le GFV a pu être détecté dans les feuilles de C. quinoa broyées dans tous les milieux utilisés, la présence de nicotine est indispensable pour que le virus puisse être détecté dans les extraits de vigne. Ces résultats ont été confirmés en immergeant des disques de $C$. quinoa et de vigne dans les différents milieux de diffusion.

\section{A. Comparaison des méthodes ELISA directe et indi- recte}

La sensibilité des méthodes ELISA directe et indirecte a été évaluée en utilisant des préparations de GFV et d'AMV purifiés. Les résultats montrent que, dans les 2 méthodes, le virus peut être détecté jusqu'à une concentration d'environ $10 \mathrm{ng} / \mathrm{ml}$ (fig. 1,2 et 3 ). Lorsque le virus purifié est dilué 4 fois dans du jus de vignes saines, cette sensibilité se trouve diminuée d'environ 10 fois.

La méthode indirecte a été comparée à la méthode directe pour la détection de l'AMV et du GFV dans des jus bruts de $C$. quinoa et de vigne. Le bruit de fond (densité optique pour les extraits de plantes saines) est toujours plus élevé d'un facteur 2 à 10 pour la méthode indirecte que pour la méthode directe. Ce bruit de fond baisse lorsque l'on diminue la concentration du conjugué chèvre anti-lapin. Le virus AMV n'est jamais détecté avec les réactifs GFV et inversement. Ceci est également vrai pour la méthode ELISA directe et pour la méthode indirecte, même lorsque l'on utilise des virus purifiés comme antigènes (fig. 2 et 3).

Lorsque les extraits sont préparés par broyage de rondelles de feuilles de plantes saines et virosées mélangées dans des proportions variables, on constate qu'il suffit la plupart du temps d'un seul disque de vigne malade ajouté à 49 disques de vigne saine pour que le virus soit détecté. Dans le cas de C. quinoa la détection est encore assurée avec un disque de feuille malade pour 99 disques de feuilles saines.

Lorsque l'on utilise des disques non broyés comme source d'antigènes, pour $C$. quinoa, il suffit d'un seul disque par cupule pour pouvoir déceler le virus, alors que pour la vigne, 5 à 8 disques par cupule sont nécessaires pour obtenir des résultats positifs.

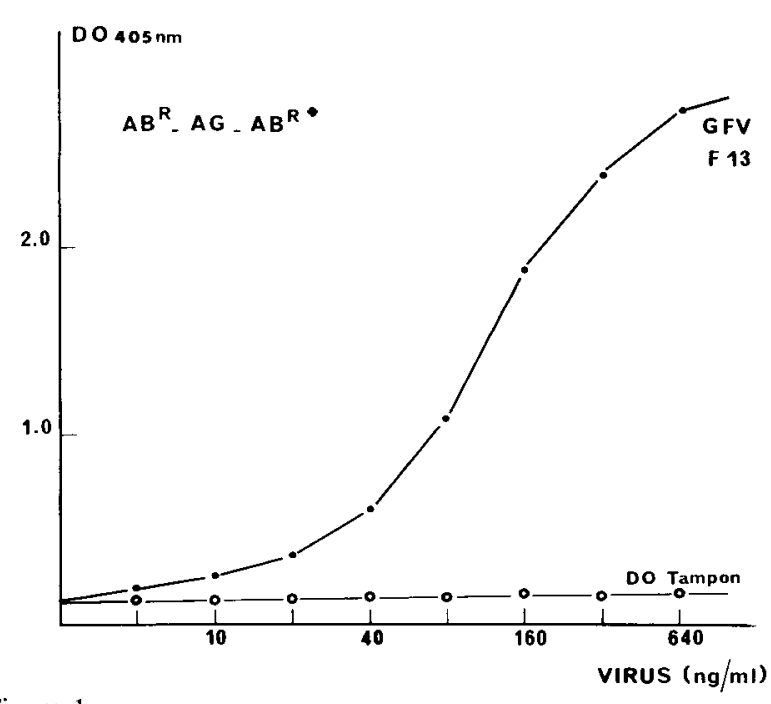

Figure 1

Détection du GFV FI3 (•-) par la méthode ELISA directe. $A B^{R}$ : anticorps de lapin GFV utilisés pour le tapissage des cupules (globulines à 2,5 $\mathrm{\mu g} / \mathrm{ml}$; incubation $5 \mathrm{~h}$ ); $A G$ : virus purifié; $A B^{R^{*}}$ : anticorps de lapin anti GFV conjugué $(1 / 400)$ incubé pendant $4 \mathrm{~h}$. (0—o): bruit de fond mesuré avec le tampon.

Detection of grapevine fanleaf virus (GFV) by direct ELISA $\left(\bullet-A B^{R}\right.$ : anti GFV rabbit antibody used for coating plates $(2.5 \mu \mathrm{g} / \mathrm{ml}$ globulins incubated for $5 \mathrm{~h})$; $A G$ : purified virus ; $A B^{R^{*}}$ : anti GFV rabbit antibody conjugate (diluted $1 / 400$ ) incubated for $4 \mathrm{~h}$. 


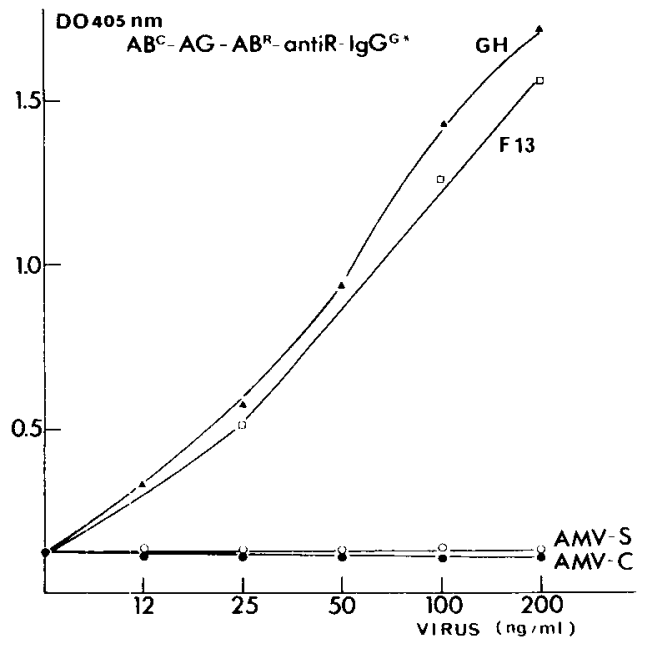

Figure 2

Détection de 2 isolats (GH et F13) du GFV par la méthode ELISA indirecte. $A B^{C}$ : anticorps de poule anti GFV utilisés pour le tapissage (globulines à $1 \mathrm{lg} / \mathrm{ml}) ; A G$ : virus purifié ; $A B^{R}$ : anticorps de lapin anti GFV (antisérum dilué $1 / 5000)$; anti $R-I g G^{G^{*}}$ : conjugué chèvre anti lapin (1/2000). Les 2 souches du virus $A M V$ (S et C) ne sont pas détectées par les anticorps anti GFV.

Detection of 2 isolates ( $G H$ and F13) of grapevine fanleaf virus (GFV) by indirect ELISA. $A B^{C}$ : anti GFV chicken antibody used for coating $\left(1 \mu \mathrm{g} / \mathrm{ml}\right.$ globuls); $A G$ : antigen; $A B^{R}$ : anti $G F V$ rabbit antiserum (diluted $1 / 5000$ ); anti $R-I g G^{G *}$ : goat anti rabbit conjugate $(1 / 2000)$. The 2 strains $(S$ and $C$ ) of arabis mosaic virus (AMV) are not detected in this test.

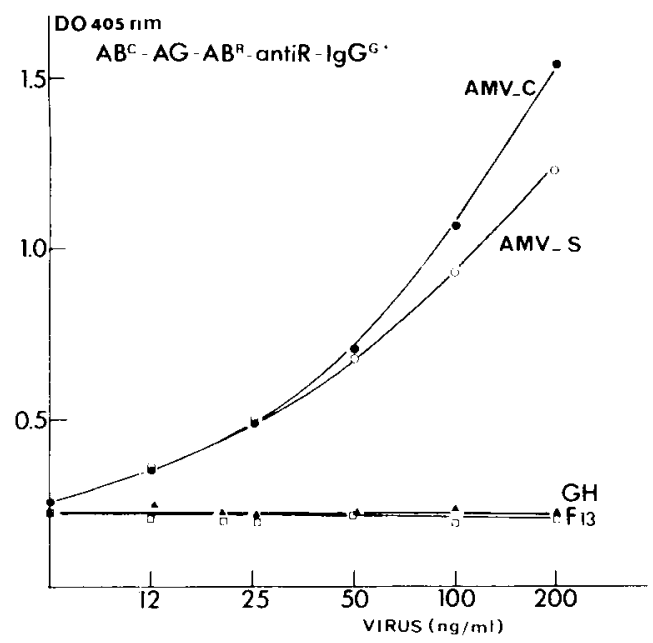

Figure 3

Détection de 2 souches ( $A M V-C$ et $A M V-S)$ de l'AMV par la méthode ELISA indirecte. $A B^{C}$ : anticorps de poule anti $A M V$ utilisés pour le tapissage (globulines à $1 \mu \mathrm{g} / \mathrm{ml}) ; A G$ : virus purifié; $A B^{R}$ : anticorps de lapin anti $A M V$ (antisérum dilué $1 / 10000$ ); anti $R$-IgG $G^{*}$ : conjugué chèvre anti lapin $(l / 2000)$. Les 2 isolats $G H$ et F13 de GFV ne sont pas détectés par les anticorps anti AMV.

Detection of 2 strains $(C$ and $S$ ) of arabis mosaic virus (AMV) by indirect ELISA. AB $B^{C}$ anti AMV chicken globulins $(1 \mu \mathrm{g} / \mathrm{ml}) ; A G$ : antigen; $A B^{R}$ : anti $A M V$ rabbit antiserum (1/10 000); anti $R$ $\operatorname{Ig} G^{G^{*}}$ : goat anti rabbit conjugate $(1 / 2000)$. The 2 isolates of GFV (GH and FI3) are not detected by AMV antibodies.

La température d'incubation des disques et l'agitation des plaques pendant cette incubation n'influent pas sur ces résultats. Avec des disques de $C$. quinoa, les virus du court-noué peuvent être détectés aisément après 15 à $30 \mathrm{mn}$ d'incubation du substrat (fig. $4 \mathrm{~A}$ ).

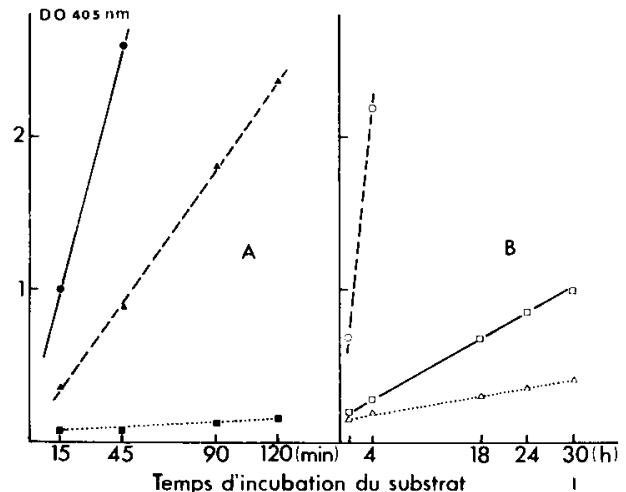

Figure 4A

Détection du GFV dans les disques de feuilles non broyées de C. quinoa par la méthode ELISA directe.

Anticorps de tapissage anti $G F V: 1,25 \mu \mathrm{g} / \mathrm{ml}$ (山) $5 \mathrm{~h}, 37^{\circ} \mathrm{C}$ et $2,5 \mathrm{\mu g} / \mathrm{ml}(\mathbf{0}) 5 \mathrm{~h}, 37^{\circ} \mathrm{C}$.

Antigènes : 3 disques de $\mathrm{C}$. quinoa sain (ם) et infecté par le $G F V$ ( $\Delta$ et ) immergés dans le tampon PBS-Tween-PVP une nuit, $20^{\circ} \mathrm{C}$, sous agitation.

Conjugué phosphatase anti GFV: 1/800 (4) et $1 / 400$ () $6 \mathrm{~h}$, $37{ }^{\circ} \mathrm{C}$. Les valeurs des $D O_{405}$ sont les moyennes de 4 répétitions par expérience.

Detection of GFV in leaf discs of $\mathrm{C}$. quinoa by direct ELISA. Coating antibody : $7.25 \mu \mathrm{g} / \mathrm{ml}(\mathbf{\Delta})$ and $2.5 \mu \mathrm{g} / \mathrm{ml}(\mathbf{O})$. Wells containing either 3 discs from healthy leaves (ם) or GFV-infected leaves ( $\Delta$ and $\mathbf{O})$. Enzyme conjugate was used at $1 / 800(\mathbf{\Delta})$ and $1 / 400$ (O) dilution. Each point represents the average of 4 measurements.

Figure 4B

Détection du GFV dans des disques de feuilles non broyées de vigne par la méthode ELISA directe.

Anticorps de tapissage : $1 \mu \mathrm{g} / \mathrm{ml}, 4 \mathrm{~h}, 37^{\circ} \mathrm{C}$

Antigènes : 8 disques de vignes saines $(\triangle)$ ou infectées par le $G F V$ () ou extrait abtenu par broyage de $1 \mathrm{~g}$ de feuille dans $4 \mathrm{ml}$ de tampon PBS-Tween-PVP-nicotine 2,5 p. 100 (口). Incubation une nuit à $4{ }^{\circ} \mathrm{C}$, sous agitation.

Conjugué phosphatase anti $\mathrm{GFV}: 1 / 800,6 \mathrm{~h}, 37^{\circ} \mathrm{C}$

Les valeurs de $\mathrm{DO}_{405}$ sont les moyennes de 4 répétitions par expérience.

Detection of GFV in leaf discs of grapevine by direct ELISA.

Coating antibody: $1 \mathrm{\mu g} / \mathrm{ml}$. Wells contained either 8 discs from healthy plants $(\triangle)$, or from $G F V$-infected plants $(\square)$, or a leaf extract $1 \mathrm{~g}$ leaf tissue ground with $4 \mathrm{ml}$ PBS-Tween-PVP buffer containing $2.5 \%$ nicotine $(O)$. The enzyme conjugate was used at 1/800 dilution. Each point represents the average of 4 measurements.

Dans le cas de la vigne, il est nécessaire de laisser incuber le substrat plus longtemps (fig. 4 B).

En comparant les méthodes sandwich directe et indirecte pour la détection des virus du court-noué dans des disques non broyés de vigne, nous avons constaté que la sensibilité de la méthode indirecte est supérieure à celle de la méthode directe. Mais, parallèlement, le bruit de fond mesuré par la méthode indirecte est, lui aussi, supérieur à celui de la méthode directe et augmente proportionnellement avec le temps d'incubation du substrat.

L'utilisation d'anticorps d'enrobage - IgG de lapin anti-virus - plus concentrés (jusqu'à $2,5 \mu \mathrm{g} / \mathrm{ml}$ ) ou de conjugués moins dilués (jusqu'à $1 / 400$ ) n'a pas permis de réduire notablement le temps d'incubation du substrat. Il en est de même avec un substrat plus concentré $(1 \mathrm{mg} / \mathrm{ml})$ ou en laissant incuber les disques de feuilles à différentes températures $\left(4^{\circ}, 20^{\circ}, 25^{\circ} \mathrm{C}\right)$. 


\section{B. Test au latex}

Les essais comparatifs avec la méthode de floculation du latex (technique PALLAS) démontrent que celle-ci est moins sensible que la technique ELISA pour la détection des virus GFV et AMV (tabl. 1). Ces essais ont été effectués sur des feuilles prélevées sur des boutures de sarments forcées en serre au cours de l'hiver (janvier 1982). De plus la technique PALLAS nécessite une certaine habitude pour la lecture des résultats de sédimentation du latex; par ailleurs, la qualité du réactif varie en fonction de l'échantillon d'immunsérum utilisé.

\section{Influence du type d'organe prélevé}

L'influence sur la détection de l'antigène viral du type d'organe prélevé a également été étudiée (tabl. 2). Les résultats montrent que, d'une part, chez des vignes forcées en serre, GFV et AMV sont détectables
TABLEAU 1

Comparaison de l'efficacité des tests sérologiques PALLAS et ELISA direct pour la détection des népovirus du court-noué dans des extraits de feuilles de vigne infectée.

Vignes forcées en serre depuis 3 mois (hiver).

Comparison of latex test (PALLAS) and ELISA for detecting AMV and $G F V$ in leaf extracts from infected vines.

Forced vines in glasshouse for 3 months (in winter).

\begin{tabular}{lccccc}
\hline \hline & & \multicolumn{4}{c}{$\begin{array}{l}\text { nb. d'échantillons reconnus infectés/ } \\
\text { nb. d'échantillons indexés }\end{array}$} \\
\cline { 3 - 6 } Echantillon Technique & GFV & p. 100 & AMV & p. 100 \\
\hline Tissu & PALLAS & $15 / 15$ & 100 & $13 / 17$ & 76 \\
infecté & ELISA & $19 / 19$ & 100 & $20 / 20$ & 100 \\
\hline $\begin{array}{l}\text { Tissu infecté } \\
\text { dilué avec }\end{array}$ & PALLAS & $17 / 23$ & 74 & $12 / 21$ & 57 \\
tissu sain & ELISA & $27 / 29$ & 90 & $17 / 26$ & 65 \\
$1 / 50$ & & & & & \\
\hline \hline
\end{tabular}

TABLEAU 2

Influence du type d'organe prélevé (feuilles ou racines) et de la durée de végétation depuis le débourrement (vignes forcées en serre ou poussant naturellement au-dehors) sur l'efficacité de détection sérologique des népovirus du court-noué.

Résultats des tests ELISA (méthode directe et indirecte) chez des vignes issues de souches malades connues ${ }^{*}$ ).

Influence of type of plant organ (leaf or root) and of growing time on serological detection of $A M V$ and GFV by direct and indirect ELISA in infected vines.

A. Vignes forcées en serre (hiver) - Forced vines in glasshouse (in winter).

\begin{tabular}{|c|c|c|c|c|c|c|c|c|c|}
\hline & \multirow{3}{*}{ Série } & \multirow{3}{*}{ Virus } & \multirow{3}{*}{ Echant. $n^{\circ}$} & \multicolumn{3}{|c|}{ Feuilles } & \multicolumn{3}{|c|}{ Racines } \\
\hline & & & & \multicolumn{2}{|c|}{ DO Elisa (1) } & \multirow{2}{*}{ Détection (2) } & \multicolumn{2}{|c|}{ DO ElISA } & \multirow{2}{*}{ Détection } \\
\hline & & & & directe & indirecte & & directe & indirecte & \\
\hline \multirow[t]{2}{*}{ Serre } & & GFV & 1 & 0,12 & 0,31 & \multirow{3}{*}{$2 / 3$} & 2,82 & 2,08 & \\
\hline & vigne & Ur & 2 & 0,08 & 0,22 & & 2,76 & 2,69 & $3 / 3$ \\
\hline \multirow[t]{3}{*}{4 mois } & greffe & AMV & 3 & 0,02 & 0,07 & & 0,25 & 1,23 & \\
\hline & \multirow{4}{*}{$\begin{array}{r}\text { Vitis } \\
\text { vinifera }\end{array}$} & \multirow{2}{*}{ GFV } & 4 & 0,09 & 0,27 & \multirow{4}{*}{$2 / 3$} & 2,41 & 1,56 & \multirow{4}{*}{$3 / 4$} \\
\hline & & & 5 & 0,03 & 0,32 & & 2,20 & 1,34 & \\
\hline \multirow[t]{2}{*}{ Serre } & & \multirow{2}{*}{ AMV } & 6 & \multirow{2}{*}{0,03} & \multirow{2}{*}{0,06} & & 0,02 & 0,00 & \\
\hline & & & 7 & & & & 1,53 & 2,83 & \\
\hline \multirow{4}{*}{2 mois } & \multirow{4}{*}{$\begin{array}{l}\text { vigne } \\
\text { porte- } \\
\text { greffe }\end{array}$} & GFY & 8 & 2,65 & 1,80 & \multirow{4}{*}{$2 / 4$} & 2,83 & 2,40 & \multirow{4}{*}{$4 / 4$} \\
\hline & & UTV & 9 & 0,03 & 1,33 & & 2,80 & 2,38 & \\
\hline & & AMV & 10 & 0,03 & 0,12 & & 0,26 & 1,62 & \\
\hline & & AMV & 11 & 0,03 & 0,00 & & 0,21 & 1,53 & \\
\hline
\end{tabular}

B. Vignes débourrées naturellement au-dehors (printemps) - Vines grown outside in spring.

\begin{tabular}{|c|c|c|c|c|c|c|}
\hline \multirow[b]{2}{*}{ Dehors } & \multirow{2}{*}{$\begin{array}{r}\text { Vitis } \\
\text { vinifera }\end{array}$} & GFV & $\begin{array}{l}12 \\
13\end{array}$ & $\begin{array}{l}2,23 \\
2,91 \\
\end{array}$ & $\begin{array}{l}1,09 \\
1,65\end{array}$ & \multirow[t]{2}{*}{$4 / 4$} \\
\hline & & AMV & $\begin{array}{l}14 \\
15\end{array}$ & $\begin{array}{l}1,62 \\
0,39\end{array}$ & $\begin{array}{l}2,48 \\
2,63\end{array}$ & \\
\hline \multirow{2}{*}{1 mois } & \multirow{2}{*}{$\begin{array}{l}\text { vigne } \\
\text { porte- } \\
\text { greffe }\end{array}$} & GFV & $\begin{array}{l}16 \\
17\end{array}$ & $\begin{array}{l}2,63 \\
2,94\end{array}$ & $\begin{array}{l}2,13 \\
2,31\end{array}$ & \multirow{2}{*}{$4 / 4$} \\
\hline & & AMV & $\begin{array}{l}18 \\
19\end{array}$ & $\begin{array}{l}0,20 \\
0,23\end{array}$ & $\begin{array}{l}1,19 \\
0,96\end{array}$ & \\
\hline
\end{tabular}

(*) Préparation des extraits : broyage au mortier de tissus $(1 \mathrm{~g})$ dans $4 \mathrm{ml}$ de PBS-T-PVP pH 7,4 $+2,5$ p. 100 nicotine.

(1) Différence entre la $\mathrm{DO}$ lue et la valeur du bruit de fond $=\mathrm{DO}_{\mathrm{C}}-\mathrm{DO}_{\mathrm{T}}$

(2) Nombre de plantes détectées / Nombre total de plantes malades testées. 
plus longtemps dans les radicelles que dans les feuilles, d'autre part, que la concentration d'antigène viral dans les feuilles est la plus élevée dans le cas de vignes débourrées, au dehors, au printemps.

Au cours d'années antérieures, il est apparu que la période de fin d'été était assez défavorable à la détection des népovirus du court-noué chez la vigne par des tests sérologiques d'immunodiffusion, probablement parce que les organes aériens ne contiennent plus assez de virus. Une tentative d'amélioration du diagnostic sérologique en arrière-saison a été effectuée par prélèvement, au vignoble, de boutures de sarments en cours d'aoûtement, de façon à obtenir le départ des bourgeons par forçage en serre après levée artificielle de la dormance.

Il ressort des résultats (tabl. 3) que la remise en végétation, induite expérimentalement, n'a pas favorisé une multiplication du virus suffisante pour assurer une meilleure détection par la technique ELISA. En effet, le pourcentage de vignes reconnues infectées n'a pas augmenté, comparé aux résultats obtenus sur des échantillons de feuilles prélevées au vignoble.

\section{DISCUSSION ET CONCLUSION}

La motivation technique et agronomique de ces essais était, d'une part, la mise au point d'un protocole de contrôle viral rapide du court-noué applicable aux lots de bois et plants déjà prêts à la vente (contrôle a posteriori de la certification), d'autre part, la vérification de l'absence du court-noué, par sondage dans les parcelles de pieds-mères, des réinfections naturelles pouvant survenir dans les sols de vignobles.
Les techniques ElisA représentent, par leur sensibilité et leur facilité d'application, un progrès évident pour le dépistage viral appliqué à la sélection sanitaire de la vigne. Les résultats obtenus sont en accord avec ceux de nombreux auteurs (GONSALVES, 1979 ; RAMSDELL et al., 1979 ; JANKULOVA et al., 1982 ; SHANMUGANATHAN \& FLETCHER, 1982). Le niveau de détection atteint par les techniques ELISA directe et indirecte est assez similaire, bien que dans certains cas une légère supériorité de la technique indirecte soit observée.

Il est généralement admis que les techniques ELISA indirectes sont plus sensibles que les techniques directes, étant donné que chaque couche supplémentaire dans le sandwich augmente le nombre de molécules liées spécifiquement et entraîne une amplification de la détection par le conjugué. Cependant, cette supériorité de la technique indirecte ne se vérifie que lorsque tous les paramètres du test ont été ajustés de façon optimale (VAN REGENMORTEL, 1983).

L'absence de réaction hétérologue est contraire à ce que l'on pouvait attendre avec la méthode ELISA indirecte qui devrait permettre la reconnaissance de virus apparentés tels que AMV et GFV.

Le gain de temps espéré par l'utilisation de disques de feuilles non broyés est inexistant du fait de la faible sensibilité de cette technique. Par contre, le groupement d'échantillons de vignes à tester est avantageux : dans ce cas, la détection d'un seul échantillon malade dans un lot de 50 est possible.

Il semble que le choix de l'échantillon ainsi que la période de l'année à laquelle ont lieu les tests sont les facteurs essentiels qui déterminent la possibilité de détecter le virus. Une amélioration évidente est obte-

TABLEAU 3

Détection du GFV et de l'AMV en arrière-saison par la méthode ELISA. Detection of GFV and AMV by ELISA in late autumn.

A. Echantillons de vignes forcées en serre (feuilles ou racines).

Samples from forced vines in glasshouse (leaves or roots).

\begin{tabular}{|c|c|c|c|c|c|c|}
\hline & & \multirow{3}{*}{$\begin{array}{c}\text { Virus éven- } \\
\text { tuellement } \\
\text { présent }\end{array}$} & \multicolumn{4}{|c|}{ Nature des tissus prélevés } \\
\hline & & & \multicolumn{2}{|c|}{ feuilles } & \multicolumn{2}{|c|}{ racines } \\
\hline & & & \multicolumn{4}{|c|}{$\begin{array}{l}\text { nb. d'échantillons reconnus infectés/ } \\
\text { nb. d'échantillons indexés }\end{array}$} \\
\hline \multirow{2}{*}{ Vitis vinifera } & sommet & $\begin{array}{l}\text { GFV } \\
\text { AMV }\end{array}$ & $\begin{array}{l}2 / 5 \\
1 / 4\end{array}$ & \multirow{2}{*}{33 p. 100} & $\begin{array}{l}1 / 2 \\
1 / 3\end{array}$ & \multirow{2}{*}{50 p. 100} \\
\hline & base & $\begin{array}{l}\text { GFV } \\
\text { AMV }\end{array}$ & $\begin{array}{l}2 / 5 \\
1 / 4\end{array}$ & & $\begin{array}{l}2 / 3 \\
1 / 2\end{array}$ & \\
\hline
\end{tabular}

B. Echantillons prélevés directement au vignoble (feuilles).

Samples from vines in vineyard (leaves).

\begin{tabular}{|c|c|c|c|}
\hline & $\begin{array}{l}\text { Virus éven- } \\
\text { tuellement présent }\end{array}$ & & $\begin{array}{l}\text { nb. d'échantillons reconnus infectés/ } \\
\text { nb. d'échantillons indexés }\end{array}$ \\
\hline Vitis porte-greffe & $\begin{array}{l}\text { GFV } \\
\text { AMV }\end{array}$ & $\begin{array}{l}4 / 5 \\
3 / 3\end{array}$ & 87,5 p. 100 \\
\hline Vitis vinifera & $\begin{array}{l}\text { GFV } \\
\text { AMV }\end{array}$ & $\begin{array}{l}4 / 7 \\
1 / 3\end{array}$ & 50 p. 100 \\
\hline
\end{tabular}


nue lorsque des radicelles, plutôt que des feuilles infectées, sont utilisées comme source de virus. Des résultats similaires ont été décrits pour d'autres virus (FORD, 1973 ; CASTEllo, 1983). Malheureusement la préparation d'extraits de racines est matériellement irréalisable à grande échelle pour des essais de routine, en dehors du cas de petites plantes cultivées en pots. Malgré la plus grande sensibilité de la technique ELISA, comparée à d'autres techniques sérologiques (VAN REGENMORTEL, 1982), elle n'est cependant pas entièrement fiable lorsque les tests sont réalisés en arrière-saison. Malgré l'insuccès de nos premiers essais, des études plus approfondies sont à poursuivre pour établir si le forçage, en liaison avec la levée artificielle de dormance (par rindite ou anaérobiose par- tielle) permettra de réactiver suffisamment la synthèse virale pour obtenir des tests positifs même en arrièresaison.

Reçu le 27 mai 1983 Accepté le 24 février 1984

\section{REMERCIEMENTS}

Les résultats des séries de tests, présentés aux tableaux 1,2 et 3 ont été obtenus à partir d'un matériel végétal constitué de vignes inoculées de virus connus (GFV ou AMV) et de vignes saines, destinées à d'autres essais. MM. R. LEGIN et P. BAss sont vivement remerciés pour les inoculations antérieures de ce matériel et les travaux techniques de production des boutures et de confection des échantillons.

\section{RÉFÉRENCES BIBLIOGRAPHIQUES}

Avrameas S., 1969. Coupling of enzymes to proteins with glutaraldehyde. Use of the conjugates for the detection of antigens and antibodies. Immunochemistry, 6, 43-52.

Barbara D. J., Clark M. F., Thresh J. M., Casper R., 1978. Rapid detection and serotyping of prunus necrotic ringspot virus in perennial crops by enzyme-linked immunosorbent assay. Ann. Appl. Biol., 90, 395-399.

Bar-Joseph M., Salomon R., 1980. Heterologous reactivity of tobacco mosaic virus strains in enzyme-linked immunosorbent assays. J. Gen. Virol., 47, 509-512.

Bovey R., Brugger J. J., Gugerli P., 1980. Detection of fanleaf virus in grapevine tissue extracts by enzyme-linked immunosorbent assay (ELISA) and immune electron microscopy (IEM). Proc. 7th Meet. Int. Council Study Viruses Virus-like Dis. Grapevine. Niagara Falls, Canada. Proc. Agric. Can., 259-275.

Castello J. D., 1983. Seasonal fluctuations of tobacco mosaic virus and tobacco ringspot virus within tissues of white ash trees. Phytopathology, 73, 361 (abstr.).

Clark M. F., Adams A. N., 1977. Characteristics of the microplate method of enzyme-linked immunosorbent assay for the detection of plant viruses. J. Gen. Virol., 34, 457-483.

Devergne J. C., Cardin L., Burckard J., Van Regenmortel M. H. V., 1981. Comparison of direct and indirect ELISA for detecting antigenically related cucumoviruses. J. Virol. Meth., 3, 193-200.

Engelbrecht D. J., 1980. Indexing grapevines for grapevine fanleaf virus by enzyme-linked immunosorbent assay. Proc. 7th Meet. Int. Council Study Viruses Virus-like Dis. Grapevine, Niagara Falls, Canada. Proc. Agric. Can., 277-282.

Ford R. E., 1973. Concentration and purification of clover yellow mosaic virus from pea roots and leaves. Phytopathology, 63, 926930.

Gonsalves D., 1979. Detection of tomato ringspot virus in grapevines : a comparison of Chenopodium quinoa and enzyme-linked immunosorbent assay (ELISA). Plant Dis. Rep., 63, 962-965.

Hardie G., Van Regenmortel M. H. V., 1977. Isolation of specific antibody under conditions of low ionic strength. J. Immunol. Methods, 15, 305-314.

Jankulova M., Eskenazy M., Bakardzhieva N., Georgieva P., 1982. ELISA for the quantitative determination of grapevine fanleaf virus. Z. Pflanz. Pflsch., 89, 18-29.

Jimenez F., Goheen A. C., 1980. The use of enzyme-linked immunosorbent assay for detection of grape fanleaf virus. Proc. 7th Meet. Int. Council Study Viruses Virus-like Dis. Grapevine, Niagara Falls, Canada. Proc. Agric. Can., 283-291.

Koenig R., 1978. ELISA in the study of homologous and heterologous reactions of plant viruses. J. Gen. Virol., 40, 309-318.

Kolber M., Lehoczky J., Kobza S., Nemeth M., Pasca S., 1980. Diagnostika virusu roncety vinica ELISA testom. Ochr. Rost., 16, 83-88 (en tchèque).
Lommel S. A., McCain A. H., Morris T. J., 1982. Evaluation of indirect enzyme-linked immunosorbent assay for the detection of plant viruses. Phytopathology, 72, 1018-1022.

Marco S., Cohen S., 1979. Rapid detection and titer evaluation of viruses in pepper by enzyme-linked immunosorbent assay. Phytopathology, 69, 1259-1262.

Polson A., Von Wechmar M. B., Van Regenmortel M. H. V., 1980. Isolation of viral IgY antibodies from yolks of immunized hens. Immunol. Commun., 9, 475-493.

Querfurth G., Paul H. L., 1979. Protein A-coated latex-linked antisera (PALLAS), new reagents for a sensitive test permitting the use of antisera unsuitable for the latex test. Phytopathol. Z., 94, 282285.

Ramsdell D. C., Andrews R. W., Gillet J. M., Morris C. E., 1979. A comparison between enzyme-linked immunosorbent assay (ELISA) and Chenopodium quinoa for detection of peach rosette mosaic virus in "Concord " grapevines. Plant Dis. Rep., 63, 74-78.

Rochow W. F., Carmichael L. E., 1979. Specificity among barley yellow dwarf viruses in enzyme immunosorbent assays. Virology, 95, 415-420.

Romaine C. P., Newhart S. R., Anzola D., 1981. Enzyme-linked immunosorbent assay for plant viruses in intact leaf tissue disks. Phytopathology, 71, 308-312.

Rybicki E. P., Von Wechmar M. B., 1981. The serology of the bromoviruses. I. Serological interrelationships of the bromoviruses, Virology, 109, 391-402.

Shanmuganathan N., Fletcher C., 1982. Enzyme-linked immunosorbent assay to detect fanleaf virus in grapevines grown in containers. Plant Dis., 66, 704-707.

Tanne E., 1980. The use of ElISA for the detection of some NEPO viruses in grapevines. Proc. 7th Meet. Int. Council Study Viruses Virus-like Dis. Grapevine. Niagara Falls, Canada. Proc. Agric. Can., 293-296.

Thresh J. M., Adams A. N., Barbara D. J., Clark M. F., 1977. The detection of three viruses of hop (Humulus lupulus) by enzymelinked immunosorbent assay (ElisA). Ann. Appl. Biol., 87, 57-65.

Uyemoto J. K., 1980. Detection of maize chlorotic mottle virus serotypes by enzyme-linked immunosorbent assay. Phytopathology, 70, 290-292.

Van Regenmortel M. H. V., 1982. Serology and Immunochemistry of Plant Viruses. Acad. Press, New York, 302 p.

Van Regenmortel M. H. V., 1983. Strategy for the control of plant virus diseases. Advances in serodiagnosis In "Control of Virus Diseases" (Kurstak E. and Marusyk R., eds.). DekKER, New York, 405-422.

Van Regenmortel M. H. V., Burckard J., 1980. Detection of a wide spectrum of tobacco mosaic virus strains by indirect enzyme linked immunosorbent assays (ELISA). Virology, 106, 327-334. 
Van Regenmortel M. H. V., Nicolaieff A., Burckard J., 1980. Detection of a wide spectrum of virus strains by indirect EuISA and serological trapping electron microscopy (Strem). Acta Hortic., 110, 107-115.

Voller A., Bartlett A., Bidwell D. E., Clark M. F., Adams A. N., 1976. The detection of viruses by enzyme-linked immunosorbent assay (ELISA). J. Gen. Virol., 33, 165-167.

Vuittenez A., 1980. The new improvements of serological methods and their possible application to detect and identify virus and viruslike diseases of the grapevine. Proc. 7th Meet. Int. Council Study Viruses Virus-like Dis. Grapevine. Niagara Falls, Canada. Proc. Agric. Can., 225-243.

Walter B., Kuszala J., Vuittenez A., 1979. Diagnostic sérologique par les tests Pallas et Elisa. Application aux virus de la rhizomanie de la betterave et du court-noué de la vigne. Ann. Phytopathol., 11 (4), 568-569. 